\title{
Adsorptive, inhibitive and thermodynamics studies on the corrosion of mild steel in the presence of Mangifera indica gums
}

\author{
Habibat F. CHAHUL*, Elijah MAJI, and Tanko B. DANAT \\ Department of Chemistry, Federal University of Agriculture, P.M.B. 2373 Makurdi, Nigeria
}

\begin{abstract}
The adsorption and inhibitive behavior of gums obtained from Mangifera indica tree was investigated at 303$333 \mathrm{~K}$ using weight loss and linear polarization measurements. The results obtained from both measurements showed that Mangifera indica gums inhibited the corrosion of mild steel in $1.0 \mathrm{M} \mathrm{HCl}$. Linear polarization measurements revealed Mangifera indica gums to inhibit both the anodic and cathodic reactions on the surface of the mild steel thereby functioning as a mixed-type inhibitor. Adsorption behavior of the gums were approximated by the isotherm models of Langmuir, Freundlich and Temkin. The adsorption mechanism derived from the trend in inhibition efficiency as a function of temperature as well as kinetic and activation parameters signified Mangifera indica gums adsorbed on the surface of the mild steel through the mechanism of physisorption and that the adsorption process was exothermic and spontaneous.
\end{abstract}

Keywords: mild steel, corrosion inhibition, gums, adsorption isotherm, activation energy.

\section{Introduction}

Extreme corrosion attack has been reportedly known to take place on the surfaces of steel deployed in service in aqueous acidic environments [1]. A lot of techniques have been engaged in proffering solution to this menace of corrosion. Amid these different techniques, an important one is the use of corrosion inhibitors [2-5].

The rate of corrosion of steel can be notably reduced by the introduction of corrosion inhibitors into the aggressive aqueous environments thereby inhibiting the corrosion process and reducing the corrosion rate. Corrosion inhibitors are chemical substances that when introduced in a little amount to a corrosive environment would significantly lower the corrosion rate of a metal/alloy [3].

Organic compounds possessing polar functions with oxygen, nitrogen, and/or sulfur in a conjugated system have been reportedly used as corrosion inhibitors [6]. Corrosion inhibitors function at the interphase formed by corrosion products involving the metal/alloy and corrosive solution, and their interaction with the corroding metal surface, frequently via adsorption which usually leads to an alteration in either the mechanism of the electrochemical process at the double layer or in the surface available to the corrosion process [6].

The high costs of a good number of corrosion inhibitors albeit the health and environmental hazards that most of them pose necessitates the exploration of a class of inexpensive and eco-friendly inhibitors as substitutes [1-6]. The use of plant products as corrosion inhibitors is a viable field of research because they are inexpensive, renewable and eco-friendly sources of important phytochemicals such as amino acids, alkaloids, flavonoids, tannins, carbohydrates and lignins.
Plants based gums are usually made up of sucrose, arabinogalactan, oligosaccharides, glycoproteins and polysaccharides which possess oxygen and nitrogen atoms which are the centers of adsorption. Most gums of plant origin also possess - $\mathrm{COOH}$ functional groups, which can increase the contribution of electron or charge transfer through adsorption of the gums on surface of the metal/alloy thereby inhibiting the corrosion process [79].

Mangifera indica (MI) commonly known as mango belongs to the family Anacardiaceae. Its gum is a dried gummy exudate polysaccharide obtained from the bark of the mango tree [10]. Gums obtained from plants have been reported as good corrosion inhibitors against the corrosion of steel in acidic environments [7-9].

This study reports on the potential of MI gums as a corrosion inhibitor against the corrosion of mild steel in 1.0 $\mathrm{M} \mathrm{HCl}$ solution. Weight loss and linear polarization measurements would be employed in this investigation.

\section{Experimental}

\subsection{Materials}

Mild steel coupons of dimension $3 \times 2 \mathrm{~cm}^{2}$ and percentage composition: $\mathrm{Si}-0.03 \%, \mathrm{P}-0.04 \%, \mathrm{~S}-0.04$ $\%, \mathrm{Mn}-0.60 \%$ and the rest Fe, were used for this study. Analar grade reagents were used for the study.

\subsection{Methods}

2.2.1 Purification of Mangifera indica gums. The procedure adopted for the purification of the gums has been reported elsewhere by Femi et al. [11, 12]. Pulverized gums were kept in a dry and air tight container. $0.05 \mathrm{~g}-0.25 \mathrm{~g}$ of the pulverized gums were used to prepare test solutions of $0.2 \mathrm{~g} / \mathrm{L}, 0.4 \mathrm{~g} / \mathrm{L}, 0.6 \mathrm{~g} / \mathrm{L}$, $0.8 \mathrm{~g} / \mathrm{L}$ and $1.0 \mathrm{~g} / \mathrm{L}$ concentrations by adding the gums to $250 \mathrm{~mL}$ of $1.0 \mathrm{M} \mathrm{HCl}$.

\footnotetext{
* Corresponding author. E-mail address: momohbat2007@gmail.com (Habibat F. Chahul)
} 
2.2.2. Weight loss measurement. Weight loss measurements have been comprehensively described elsewhere [13]. Already cleaned and weighed coupons made from steel were suspended in $250 \mathrm{~mL}$ of the test solutions. Measurements were carried out in duplicates in order to obtain reproducible results. Effect of exposure time on the corrosion rate of the mild steel was investigated by carrying out the experiment for $24 \mathrm{~h}, 48$ h, 72 h, 96 h, 120 h, $144 \mathrm{~h}$ and 168 h. Temperature studies were conducted for three hours at $303 \mathrm{~K}, 313 \mathrm{~K}$, $323 \mathrm{~K}$ and $333 \mathrm{~K}$ using a thermostatic water bath. The loss in weight was taken to be the difference in weights of the coupon at a given time and its initial weight.

2.2.3. Linear polarization measurements. Linear polarization studies were carried out using Metrohm Autolab AUT50280 in the potential range of -1500 to $1500 \mathrm{mV}$ with a scan rate of $0.012 \mathrm{v} / \mathrm{s}$ at room temperature [14].

Mild steel coupons of $3 \times 2 \mathrm{~cm}^{2}$ dimension were covered with epoxy resin in such a way that only $1 \mathrm{~cm}^{2}$ surface area was left uncovered. A three-electrode flask containing a mild steel working electrode, saturated calomel electrode (SCE) as reference electrode and platinum $(\mathrm{Pt})$ as an auxiliary electrode, was employed for the measurements.

2.2.4. Optical microscopy. Surface morphologies of mild steel coupons before and after dissolution for 24 hours in the absence and presence $1.0 \mathrm{~g} / \mathrm{L}$ of MI gums were investigated using a metallurgical microscope (Tsview digital metallurgical microscope, Tucsen 0923502 model) [14].

\section{Results and discussion}

\subsection{Weight loss data}

The corrosion rate $(C R)$, inhibition efficiency $(\% I E)$ and degree of surface coverage $(\theta)$ were calculated using Equations 1 to 3 respectively [13].

$$
\begin{aligned}
& C R\left(\mathrm{gh}^{-1} \mathrm{~cm}^{-2}\right)=\frac{\Delta W}{A t} \\
& I E_{\exp }=\left(1-\frac{W_{1}}{W_{2}}\right) x 100 \\
& \theta=1-\frac{W_{1}}{W_{2}}
\end{aligned}
$$

where $W_{1}$ and $W_{2}$ are the weight losses (g) of mild steel in the presence and absence of the inhibitor, $\Delta W=W_{2}$ $W_{1}$ is the weight loss of mild steel after time, $t, A$ is the area of the metal coupon (in $\mathrm{cm}^{2}$ ), $t$ is the exposure period (in hours) and $\theta$ is the degree of surface coverage of the inhibitor. The presented data are the average of duplicate measurements.

Figure 1 depicts the corrosion rate of mild steel in the test solutions as a function of exposure time. It can be observed from the plot on Figure 1 that the corrosion rate of mild steel decreased with exposure time and increasing concentrations of MI gums while inhibition efficiency increased with increasing concentrations of MI gums up to the exposure time of $72 \mathrm{~h}$ before a decrease (Figure 2) to about $70 \%$ at the optimum concentration of $1.0 \mathrm{~g} / \mathrm{L}$ at the end of the experiment (168 h).

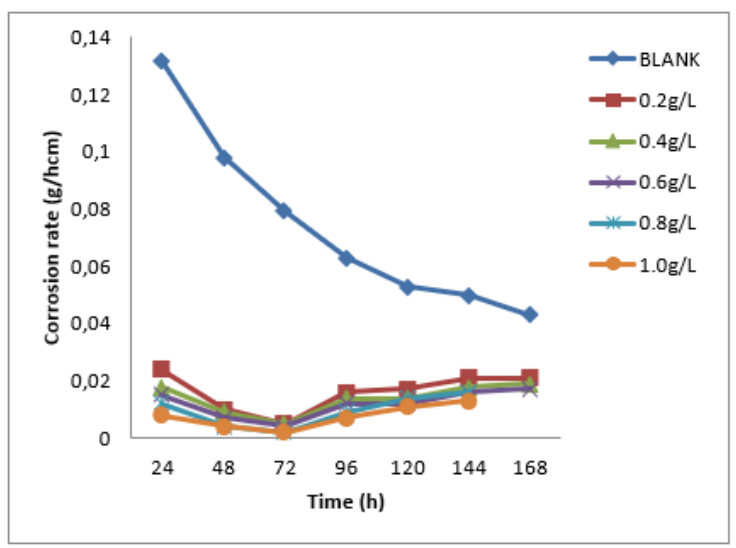

Figure 1. Corrosion rate of mild steel as a function of exposure time.

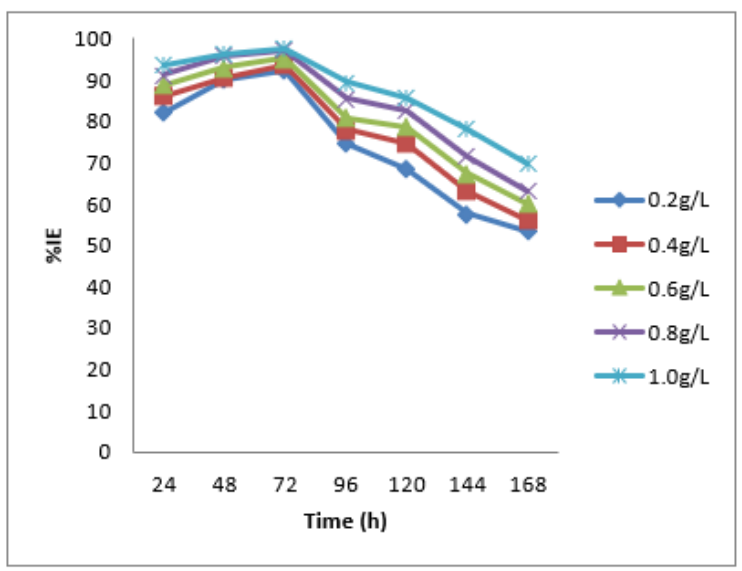

Figure 2. Inhibition efficiency of MI gums as a function of exposure time.

This development has been ascribed to the desorption of the inhibitor from the surface of the steel at longer exposure time leading to lower $I E$ values observed $[2,6,16]$.

Table 1. Corrosion rate of mild steel coupons in $1.0 \mathrm{M} \mathrm{HCl}$ at $303-333 \mathrm{~K}$.

\begin{tabular}{lcccc}
\hline Concentration $(\mathrm{g} / \mathbf{L})$ & \multicolumn{4}{c}{ Corrosion rate $\left(\mathbf{g} \cdot \mathbf{h}^{-\mathbf{1}} \cdot \mathbf{c m}^{\mathbf{2}}\right)$} \\
\hline & $\mathbf{3 0 3 ~ K}$ & $\mathbf{3 1 3 ~ K}$ & $\mathbf{3 2 3 ~ K}$ & $\mathbf{3 3 3 ~ K}$ \\
Blank & 0.263 & 0.505 & 0.843 & 1.050 \\
$\mathbf{0 . 2}$ & 0.103 & 0.139 & 0.200 & 0.228 \\
$\mathbf{0 . 4}$ & 0.086 & 0.120 & 0.169 & 0.214 \\
$\mathbf{0 . 6}$ & 0.071 & 0.107 & 0.160 & 0.178 \\
$\mathbf{0 . 8}$ & 0.057 & 0.091 & 0.123 & 0.159 \\
$\mathbf{1 . 0}$ & 0.049 & 0.069 & 0.097 & 0.121 \\
\hline
\end{tabular}

Table 1 presents the values of the corrosion rate of mild steel in $1.0 \mathrm{M} \mathrm{HCl}$ solutions at $303,313,323$ and $333 \mathrm{~K}$. A closer look at the values of corrosion rates on Table 1, it is evident that the corrosion rates of mild steel generally increased with increase in temperature both in the absence and presence of MI gums. This is because as the temperature increased from 303 to $333 \mathrm{~K}$, the rate of corrosion of the mild steel coupons also increased due to increasing average kinetic energy of the reacting molecules $[2,16]$. However, the corrosion rate of mild steel was relatively lower in the presence of MI gums compared with the uninhibited $\mathrm{HCl}$ solution. This 
signifies the inhibitive effect of MI gums on the corrosion of mild steel in the acid solution.

Figure 3 illustrates the quantitative effect of this inhibitive effect of MI gums with increasing temperature. The plot shows that $I E$ decreased with increase in temperature, a phenomenon that has been reportedly associated with the physisorptive kind of adsorption mechanism of an inhibitor to the surface of a metal/alloy $[3,13,16]$.

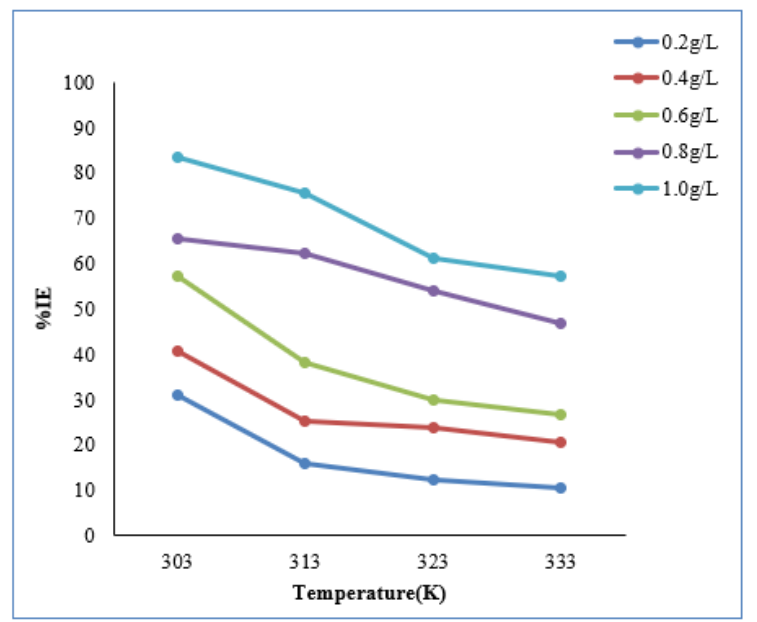

Figure 3. Inhibition efficiency of MI gums as a function of temperature $(\mathrm{K})$.

\subsection{Linear polarization}

The effect of MI gums on the corrosion of mild steel in 1.0 M solution of $\mathrm{HCl}$ was also investigated using linear polarization. Figure 4 shows the linear polarization plots. The linear polarization parameters derived from the polarization plots and inhibition efficiency values quantified using Equation 4 are summarized on Table 2.

$$
\% I E=\frac{I_{\operatorname{corr}(\operatorname{blnk})-I_{\operatorname{corr}(i n h)}}}{I_{\operatorname{corr}(\operatorname{blnk})}} \times 100
$$

where $I_{\text {corr }(b \operatorname{lnk})}$ is the corrosion current density of MS without inhibitor and $I_{\operatorname{corr}(i n h)}$ is the corrosion current density of MS with inhibitor.

The corrosion current density determines the reactivity of a metal in an aqueous environment. The higher the values of $I_{\text {corr }}$, the higher the dissolution of the metal and vice versa. The presence of MI gums was found to influence to both the anodic and cathodic redox reactions, shifting the corrosion potential $\left(E_{\text {corr }}\right)$ toward more negative (cathodic) values thereby reducing the anodic $\left(b_{a}\right)$ and cathodic $\left(b_{c}\right)$ current densities and the corresponding corrosion current density. This implies that MI gums behaved as a mixedtype inhibitor [16].

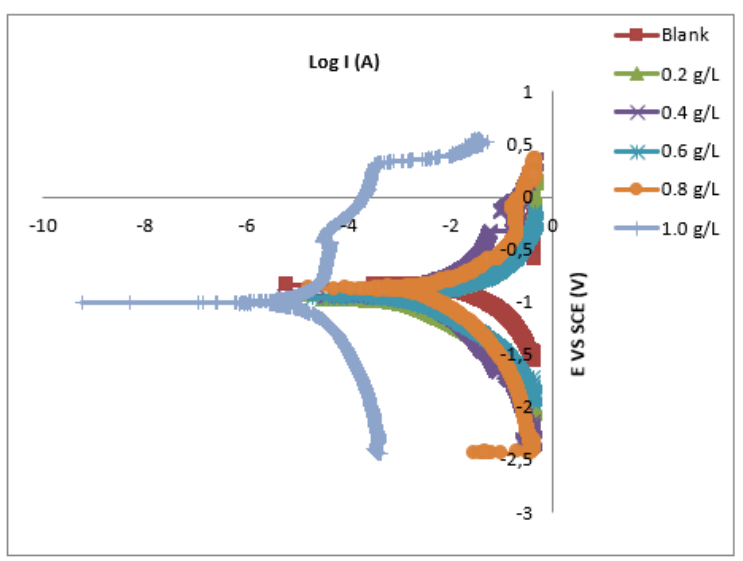

Figure 4. Linear polarization plots of the corrosion of mild steel in $1.0 \mathrm{M} \mathrm{HCl}$ in the absence and presence of MI.

Table 2. Linear polarization parameters for the corrosion of mild steel in $1.0 \mathrm{M} \mathrm{HCl}$ in the absence and presence of MI.

\begin{tabular}{|c|c|c|c|c|}
\hline $\begin{array}{c}\text { Conc. } \\
(\mathbf{g} / \mathbf{L})\end{array}$ & $\begin{array}{c}\mathbf{E}_{\text {corr }} \\
(\mathbf{m V})\end{array}$ & $\begin{array}{c}\mathbf{I}_{\text {corr }} \\
(\boldsymbol{\mu} \mathbf{A} / \mathbf{c m})\end{array}$ & $\begin{array}{c}\text { CR } \\
(\mathbf{m m} / \text { year })\end{array}$ & $\begin{array}{c}\text { IE } \\
(\boldsymbol{\%})\end{array}$ \\
\hline Blank & -843.79 & 299.86 & 348.44 & - \\
\hline 0.2 & -976.54 & 68.89 & 80.044 & 77.03 \\
\hline 0.4 & -942.07 & 29.06 & 33.768 & 90.31 \\
\hline 0.6 & -953.81 & 56.71 & 65.80 & 81.09 \\
\hline 0.8 & -880.79 & 58.65 & 68.149 & 80.44 \\
\hline 1.0 & -1010.30 & 54.50 & 63.364 & 99.82 \\
\hline
\end{tabular}

\subsection{Optical microscopy}

Fig. 5 shows the optical micrograph of the surface of the steel coupon in the free acid, while Fig. 6 is the optical micrograph of the surface of the steel coupon with 1.0 g/L MI gums. Fig. 5 shows a surface morphology that is severely damaged compared to Fig. 6 . This is due to the rust formed on it after undergoing acidic attack in $1.0 \mathrm{M}$ solution of $\mathrm{HCl}$. The steel surface in Fig. 6 is absent of cracks and pits except for some polishing lines and the evidence of a very reasonable amount of protective films of MI gums thus confirming the adsorptive and inhibitive properties of MI gums.

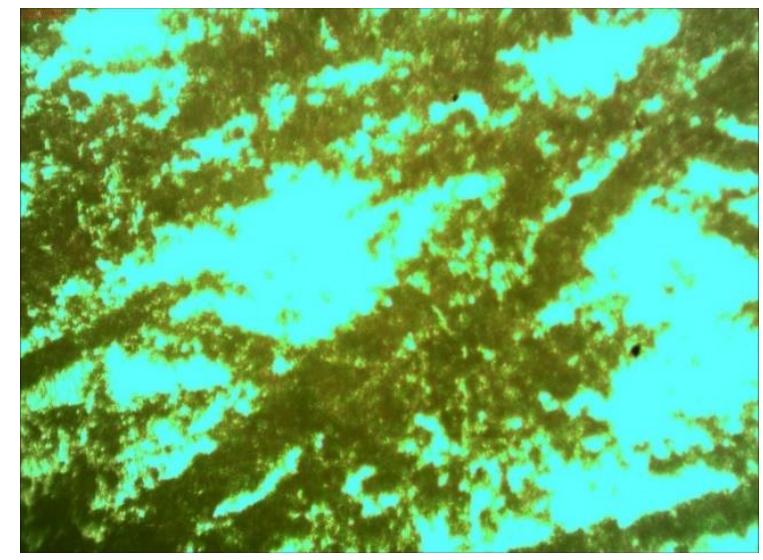

Figure 5. Micrograph of steel surface after exposure for $24 \mathrm{~h}$ in $1.0 \mathrm{M} \mathrm{HCl}$. 


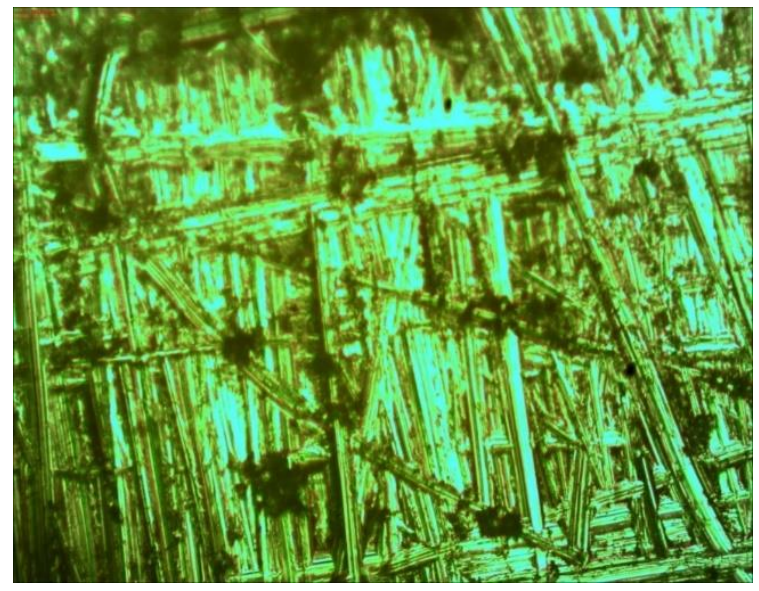

Figure 6. Micrograph of steel surface after exposure for $24 \mathrm{~h}$ in $1.0 \mathrm{M} \mathrm{HCl}$ with $1.0 \mathrm{~g} / \mathrm{L} \mathrm{MI}$ gums.

\subsection{Adsorption mechanism}

In trying to identify the adsorption properties of MI gums on the surface of the mild steel, values of $\theta$ obtained from weight loss experiments at 303 and 333 $\mathrm{K}$ were inserted into different isotherm models, the linearity of the plots and the coefficients of correlation $\left(R^{2}\right)$ were employed in determining the finest fit. The Langmuir, Freundlich and Temkin adsorption isotherms gave the best fit (Figures 7-9).

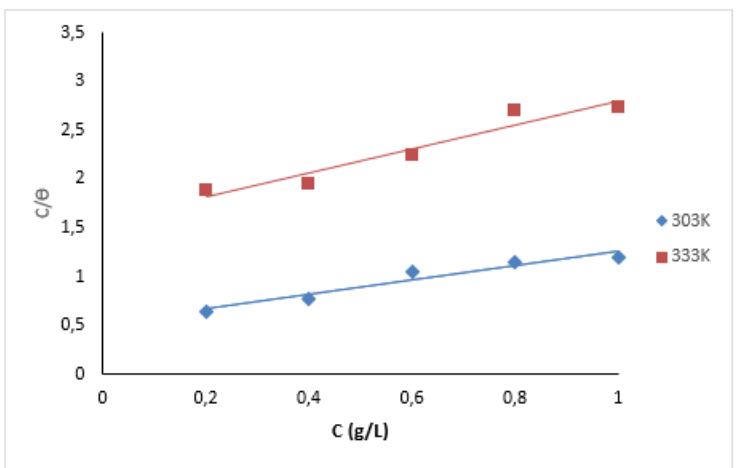

Figure 7. Langmuir isotherm for the adsorption of MI on mild steel surface in $1.0 \mathrm{M} \mathrm{HCl}$.

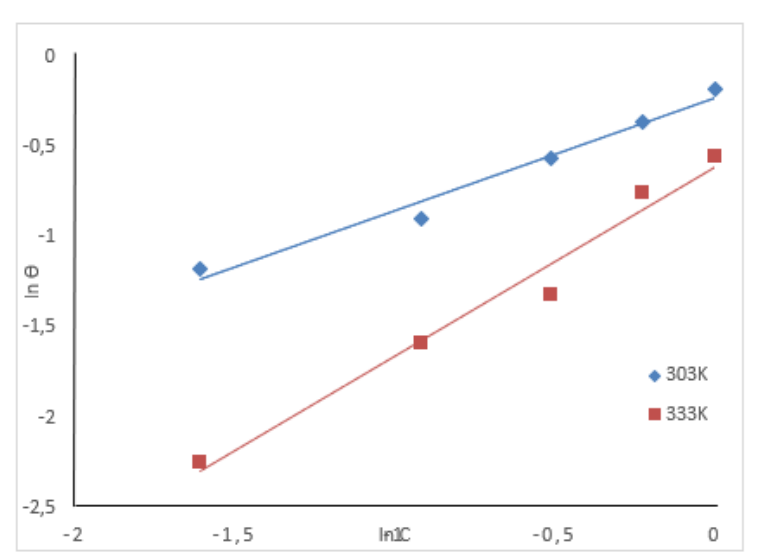

Figure 8. Freundlich isotherm for the adsorption of MI on the mild steel surface in $1.0 \mathrm{M} \mathrm{HCl}$.

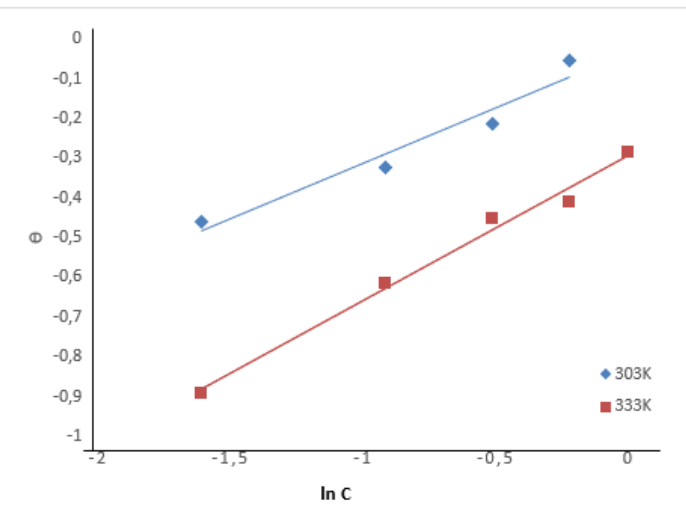

Figure 9. Temkin isotherm for the adsorption of MI on the mild steel surface in $1.0 \mathrm{M} \mathrm{HCl}$.

The isotherm models can be mathematically expressed as $[13,16]$ :

$$
\begin{gathered}
\frac{C}{\theta}=C+\frac{1}{K_{a d s}} \\
\log \theta=\log K_{a d s}-n \log C \\
-2 \propto \theta=2.303\left(\log K_{a d s}+\log C\right)(7) \text { Temkin }
\end{gathered}
$$

where $C$ is the concentration of MI gums in the bulk electrolyte, $K_{\text {ads }}$ is the adsorption equilibrium constant, $\theta$ is the degree of surface coverage of MI gums, $n$ is the Freundlich constant and $\propto$ is the molecular interaction parameter. Table 3 presents the adsorption parameters derived from the plots on Figures 7-9.

The adsorption equilibrium constant, $K_{a d s}$ is related to the standard free energy of adsorption, $\Delta G_{a d s}^{\circ}$ as shown in Equations 8 and 9 [13]:

$$
\begin{gathered}
\log K_{a d s}=-1.744-\frac{\Delta G_{a d s}^{\circ}}{2.303 R T} \\
\Delta G_{a d s}=-2.303 \times R T \log \left(55.5 K_{a d s}\right)
\end{gathered}
$$

where $\Delta G_{a d s}^{\circ}$ is the standard free energy of adsorption of MI gums on the mild steel surface, $R$ is the universal gas constant, 55.5 is the concentration of water in solution in $\mathrm{mol} / \mathrm{L}$ and $K_{\text {ads }}$ is the equilibrium constant of adsorption.

The values of the standard free energy of adsorption were negative and less than $-20 \mathrm{~kJ} \cdot \mathrm{mol}^{-1}$ for all the three isotherms. This shows that the adsorption of MI gums on the surface of the mild steel coupon is spontaneous and aligns with physisorption [2-5].

Table 3. Adsorption parameters of MI on mild steel surface in $1.0 \mathrm{M} \mathrm{HCl}$.

\begin{tabular}{|l|c|c|c|c|c|c|}
\hline Isotherm & $\begin{array}{c}\mathbf{T} \\
(\mathbf{K})\end{array}$ & Slope & $\boldsymbol{R}^{\mathbf{2}}$ & $\boldsymbol{K}_{\text {ads }}$ & $\boldsymbol{\alpha}$ & $\begin{array}{c}\Delta \mathbf{G}_{\text {ads }} \\
\left(\mathbf{k J ~ m o l}^{-1}\right)\end{array}$ \\
\hline Langmuir \\
\hline & 303 & 0.904 & 0.991 & 5.917 & & -14.60 \\
\hline & 333 & 1.076 & 0.990 & 3.623 & & -21.07 \\
\hline Freundlich \\
\hline & 303 & 0.280 & 0.945 & 0.924 & & -9.921 \\
\hline & 333 & 0.366 & 0.990 & 0.509 & & -9.250 \\
\hline Temkin & 303 & 0.150 & 0.975 & 0.150 & 37.70 & -25.07 \\
\hline & 333 & 0.204 & 0.985 & 0.204 & 36.34 & -21.07 \\
\hline
\end{tabular}




\subsection{Thermodynamics}

Using the values of the corrosion rates of the steel coupons at different temperatures (Table 1) and the Arrhenius equation (Equation 10), the activation energies of the corrosion of mild steel in $1.0 \mathrm{M} \mathrm{HCl}$ in the absence and presence of MI gums was evaluated.

$$
C R=A \cdot \exp ^{-E_{a} / R T}
$$

Taking the logarithm of both sides of equation 10 , Equation 11 is obtained.

$$
\log C R=\log A-\frac{E_{a}}{2.303 R T}
$$

where $C R$ is the corrosion rate of the mild steel, $A$ is the Arrhenius constant, $E_{a}$ is the activation energy, $R$ is the universal gas constant and $T$ is the absolute temperature of the system in Kelvin (K). A plot of $\log C R$ versus $1 / T$ represented on Figure 10 gave a straight line graph with a slope of $\left(-\frac{E_{a}}{2.303 R}\right)$ and an intercept of $[\log A]$ from which the values of the apparent activation energy $\left(E_{a}\right)$ were evaluated.

Table 4 presents $E_{a}$ values obtained from the plot. From Table 4, it can be observed that the value of $E_{a}$ in the uninhibited system increased when MI gums were introduced into the acid solutions. This behavior is suggestive of a physisorptive kind of adsorption mechanism whereby increase in temperature results in the desorption of the adsorbed inhibitor from the surface of the steel thereby exposing the steel surface to the acid solution and leading to an increase in the corrosion rate of the steel [13].

The values of enthalpy $\left(\Delta H^{*}\right)$ and entropy $\left(\Delta S^{*}\right)$ of activation of the corrosion inhibition process were evaluated from the Eyring equation:

$$
\begin{gathered}
\log C R / T=\left[\log (R / n h)+\Delta S^{*} / 2.303 R\right]- \\
\Delta H^{*} / 2.303 R T
\end{gathered}
$$

where $C R$ is the corrosion rate at temperature $T, R$ is the molar gas constant, $n$ is Avogadro's constant $6.0225 \times$ $10^{23}$ and $h$ is the Planck's constant $(6.6261 \times$ $10^{-34} \mathrm{Js}$ ). A plot of $\log C R / T$ versus $1 / T$ as shown on Figure 11 is a straight line graph with a slope of $\left(-\Delta H^{*} / 2.303 R\right)$ and an intercept of $[\log (R / n h)+$ $\left.\Delta S^{*} / 2.303 R\right]$ from which the values of $\Delta H^{*}$ and $\Delta S^{*}$ were calculated [13, 17-19].

The results presented on Table 4 show that the enthalpies of activation are all negative which signifies that the process of the dissolution of the mild steel was exothermic. Also, the entropies of activation were negative for the gums. Negative values of $\Delta S^{*}$ have been reported to characterize the association mechanism of the corrosion process whereby a decrease in disorder takes place on going from the reactants to the activated complex [17-20].

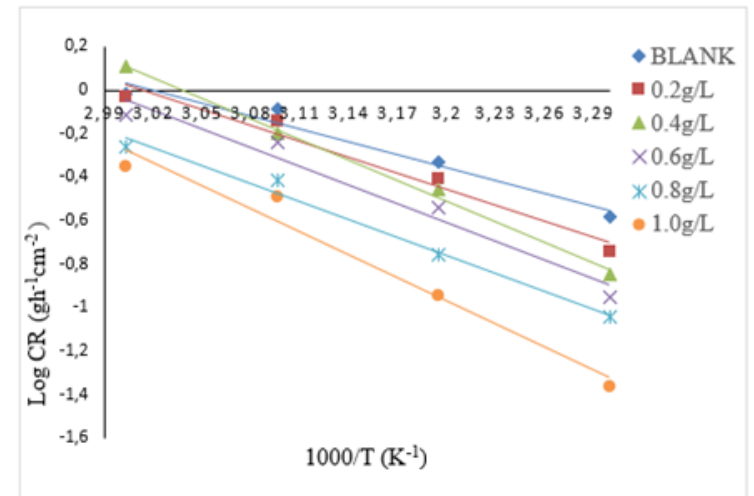

Figure 10. Arrhenius plot of the temperature-dependence of the corrosion rate of mild steel in $1.0 \mathrm{M} \mathrm{HCl}$.

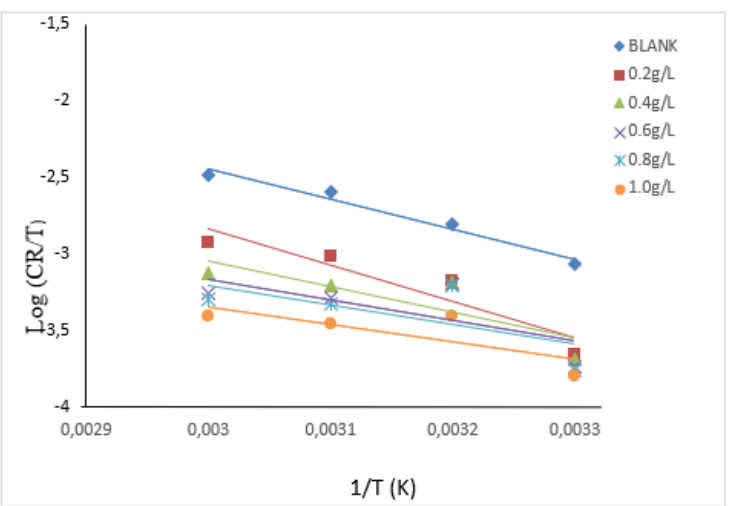

Figure 11. Eyring plot of the temperature-dependence of the corrosion rate of mild steel in $1.0 \mathrm{M} \mathrm{HCl}$.

Table 4. Activation parameters for the corrosion of mild steel in $1.0 \mathrm{M} \mathrm{HCl}$ with and without MI gums.

\begin{tabular}{|c|l|l|l|}
\hline $\begin{array}{c}\text { Concentration } \\
(\mathbf{g} / \mathbf{L})\end{array}$ & $\begin{array}{c}\mathbf{E}_{\mathbf{a}} \\
\left(\mathbf{k J} \cdot \mathbf{m o l}^{-\mathbf{1}}\right)\end{array}$ & $\begin{array}{c}\Delta \mathbf{H}^{*} \\
\left(\mathbf{k J} \cdot \mathbf{m o l}^{\mathbf{1}}\right)\end{array}$ & $\begin{array}{c}\Delta \mathbf{S}^{*} \\
\left(\mathbf{k J} \cdot \mathbf{m o l}^{\mathbf{- 1}}\right)\end{array}$ \\
\hline Blank & 16.28 & 37.49 & -131.9 \\
\hline 0.2 & 18.27 & 45.06 & -116.4 \\
\hline 0.4 & 18.56 & 31.92 & -159.6 \\
\hline 0.6 & 19.56 & 25.95 & -180.4 \\
\hline 0.8 & 20.84 & 24.07 & -186.9 \\
\hline 1.0 & 22.52 & 21.92 & -195.9 \\
\hline
\end{tabular}

\section{Conclusion}

MI gums suppressed the corrosion of mild steel in $1.0 \mathrm{M}$ solution of $\mathrm{HCl}$. Linear polarization measurements revealed MI gums to inhibit both the rates of the cathodic hydrogen ion reduction and anodic metal dissolution reactions on the surface of the mild steel thereby functioning as a mixed-type inhibitor. Adsorption behavior of the gums were approximated by the isotherm models of Langmuir, Freundlich and Temkin. Thermodynamics considerations showed that MI gums adsorbed on the surface of the mild steel through the mechanism of physisorption and that the adsorption process was exothermic and spontaneous.

\section{Conflict of interest}

The interests of the authors do not conflict.

\section{References}

[1]. E.E. Oguzie, Corrosion Inhibitive Effect and adsorption behaviour of Hibiscus sabdariffa 
extract on mild steel in acidic media, Portugaliae Electrochimica Acta 26 (2008) 303-314.

[2]. E.E. Oguzie, Inhibition of acid corrosion of mild steel by Telfiaria occidentalis extract, Pigment Resin Technology 34 (2005) 321-326.

[3]. H.F. Chahul, G.I. Ndukwe, S.T. Abawua, Corrosion inhibition studies of mild steel with stem bark extract of Maranthes Polyandra (benth.) prance, Journal of Chemical Society of Nigeria 42 (2017) 55-61.

[4]. P.C. Okafor, M.E. Ikpi, I.E. Uwah, E.E. Ebenso, U.J. Ukpe, S.A. Umeron, Inhibitory action of Phyllanthus amarus extract on the corrosion of mild steel in acidic media, Corrosion Science 50 (2008) 2310-2317.

[5]. N.O. Eddy, S.A. Odoemelam, A.O. Odiongenyi, Inhibitive, adsorptive and synergistic studies on ethanol extracts of Gnetum africana as green corrosion inhibitor for mild steel in $\mathrm{H}_{2} \mathrm{SO}_{4}$, Green Chemistry Letters and Reviews 2 (2009) 111-119.

[6]. E.E. Oguzie, C.B. Adindu, C.K. Enenebeaku, C.E. Ogukwe, M.A. Chidiebere, K.L. Oguzie, Natural products for materials protection: mechanism of corrosion inhibition of mild steel by acid extracts of Piper guineense, The Journal of Physical Chemistry C 116 (2012) 13603-13615.

[7]. A. Peter, I.B. Obot, S.K. Sharma, Use of natural gums as green corrosion inhibitors: an overview, International Journal of Industrial Chemistry 6 (2015) 153-164.

[8]. N.O. Eddy, P.O. Ameh, E.E. Ebenso, Chemical information from GCMS of Ficus platphylla gum and its corrosion inhibition potential for mild steel in $0.1 \mathrm{M} \mathrm{HCl}$, International Journal of Electrochemical Science 7 (2012) 5677-5691.

[9]. P.O. Ameh, Inhibitory action of Albizia zygia gum on mild steel corrosion in acidic medium, African Journal of Pure and Applied Chemistry 8 (2014) 37-46.

[10]. K.S. Anoop, R. Pannerselvam, T. Sivakumar, Isolation, characterisation and formulation properties of a new plant gum obtained from Mangifera indica, International Journal of Pharmaceutical and Biomedical Research 2 (2000) 35-41.

[11]. M. Femi-Oyewole, O. Musiliu, O. Taiwo, Evaluation of the suspending properties of Albizia zygia gum on sulphadimidine suspension, Tropical Journal of Pharmaceutical Research 3 (2004) 279284.
[12]. A.M. Jao, Physicochemical and rheological characterization of some plant gum exudates and their inhibition of the corrosion of aluminium in acidic medium, M.Sc. Thesis Ahmadu Bello University Zaria, Nigeria, 2014.

[13]. H.F. Chahul, A.M. Ayuba, S. Nyior, Adsorptive, kinetic, thermodynamic and inhibitive properties of Cissus populnea stem extraction the corrosion of aluminium in $\mathrm{HCl}$, ChemSearch Journal 1 (2015) 20-30.

[14]. G.A. Ijuo, N. Surma, S.O. Oloruntoba, Corrosion inhibition potential of Terminalia avicennioides extract on mild steel in $1.0 \mathrm{M} \mathrm{HCl}$ : kinetics, thermodynamics and synergistic studies, World Scientific News 102 (2018) 1-16.

[15]. M.T. Alhaffar, S. Umoren, I.B. Obot, S.A. Ali, Isoxazolidine derivatives as corrosion inhibitors for low carbon steel in $\mathrm{HCl}$ solution: Experimental, theoretical and effect of KI studies, Royal Society of Chemistry Advances 8 (2018) 1764-1777.

[16]. E.E. Oguzie, I.M. Mejeha, M.C. Nwandu, K.B. Okeoma, L.A. Nnanna, M.A. Chidiebere, F.C. Eze, Experimental and theoretical assessment of the inhibiting action of Aspilia africana extract on corrosion of aluminium alloy AA3003 in hydrochloric acid, Journal of Materials Science 47 (2012) 2559-2572.

[17]. E.F. Olasehinde, S.J. Olusegun, A.S. Adesina, S.A. Omogbehin, H. Momoh-Yahaya, Inhibitory action of Nicotiana tabacum extracts on the corrosion of mild steel in $\mathrm{HCl}$ : Adsorption and thermodynamics study, Nature and Science of Sleep 11 (2013) 8390.

[18]. M.H. Refat, A.Z. Ishaq, Kinetics of corrosion inhibition of aluminium in acidic media by watersoluble natural polymeric pectates as anionic polyelectrolyte inhibitors, Materials 6 (2013) 2436-2451.

[19]. S.S. Shukla, E.E. Eno, Corrosion inhibition, adsorption behaviour and thermodynamic properties of streptomycin on mild steel in hydrochloric acid medium, International Journal of Electrochemical Science 6 (2011) 3277 - 3291.

[20]. I.B. Obot, N.O. Obi-Egbedi, Fluconazole as an inhibitor for aluminium corrosion in $0.1 \mathrm{M} \mathrm{HCl}$, Colloids and Surfaces A: Physicochemical Engineering Aspects 330 (2008) 207-212.

Received: 19.03.2019

Received in revised form: 03.07.2019

Accepted: 22.07.2019 